\title{
Socioeconomic Inequalities of Low Back Pain in Middle Age Income People
}

\author{
Dr. Md Anamul Haque Milton ${ }^{1 *}$, Dr. Syed Ariful Islam², Dr. MD. Mazharul Alam³ ${ }^{3}$ Dr. Muhammad Shamsul Arefin ${ }^{4}$
}

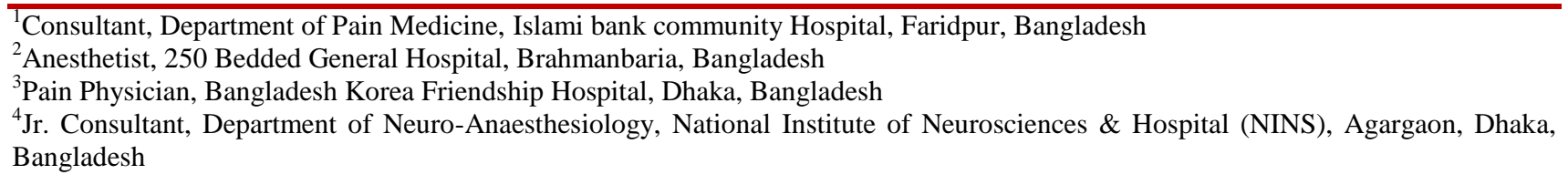

DOI: $10.36347 /$ sjams.2022.v10i01.015

| Received: 11.12.2021 | Accepted: 15.01.2022 | Published: 19.01.2022

*Corresponding author: Dr. Md Anamul Haque Milton

Consultant, Department of Pain Medicine, Islami bank community Hospital, Faridpur, Bangladesh

Abstract

Original Research Article

Background: Low back pain (LBP) is the most common medical problem in the world. Undoubtedly one of the major problems among both Middle and high-aged people is low back pain. Especially among the office-going class. This study focuses on whether social status and low back pain in middle age people have a relationship. Objective: The study aimed to evaluate the Socioeconomic Inequalities of Low Back Pain in Middle Age Income People. Methods: The data of this study were collected between July 2017 to June 2018 among the people of Bangladesh who were aged over 45 and above and all of them were functionally independent. To be exact, the number of Studies was 101 people. With a robust variance estimator, the relationship between socio-economic status and low back pain was investigated using multilevel Poisson regression analysis. The dependent variable was self-reported cases of low back pain in the previous year. Educational attainment, but occupation, equivalent household income, wealth, and subjective economic situation Where are the indicators of socioeconomic status. These indicators were independently and separately analyzed as an independent variable after regulating for covariants such as age and gender. Statistical analyses of the result were obtained by using Windows-based computer software devised with Statistical pages for social science (SPSS-24). Result \& Conclusions: Significant socioeconomic despair of low back pain was observed among middleincome earning individuals in Bangladesh. The nature of these inequalities must be understood by physicians to come up with a proper solution and overcome this challenge.

Keywords: Income; Subjective economic situation; Occupation; Low back pain; Socioeconomic status; Health inequalities.

Copyright $\odot 2022$ The Author(s): This is an open-access article distributed under the terms of the Creative Commons Attribution 4.0 International License (CC BY-NC 4.0) which permits unrestricted use, distribution, and reproduction in any medium for non-commercial use provided the original author and source are credited.

\section{INTRODUCTION}

Among the aged population, a significant issue of socio-economic inequalities was developed [1, 2]. Recent investigations have identified such symptoms of differences including musculoskeletal problems and illnesses [3-6]. Overall, musculoskeletal pain affects diseases among people and dysfunctional conditions including depression [7], dementia [8], drops [9], and disabilities [5]. The estimated one-year prevalence in the adult population is $38.0 \% \pm 19.4 \%$ and it is much higher in older groups based on a systemic evaluation of the prevalence of low back pain [10]. Different studies have identified socioeconomic discrepancies in low back pain risk variables [11-14] as depression [15], obesity [16], and smoking [16]. The results of earlier researches on socioeconomic status (SES) with low back pain were, however, conflicting. The lowest income levels have been strongly related to low back pain in comparison with the highest incomes in recent large cross-sectional studies in the United States [6]. Another cross-sectional study from France, on the contrary, showed that educational achievement is not linked to low back pain [17]. There are various features of socioeconomic status (SES) indicators that explain the difference in findings; income is a proxy of the present socioeconomic status (SES) and education is a proxy of the previous socioeconomic status (SES). Occasionally the relationships between various socioeconomic status (SES) characteristics and low back pain have been studied. We did a cross-sectional study to assess the association among older Japanese adults of past and present socioeconomic status (SES) with low back pain. 


\section{METHODS}

The study was conducted on Bangladeshi people and the data was collected between July 2017 to June 2018. The study included 101 functionally independent adult individuals aged between 45 and over. The association between socioeconomic status and low back pain was investigated using multilevel Poisson regression analysis with a robust variance estimator. The dependent variable was the cases of selfreported low back pain in the previous year. Socioeconomic status was represented by educational attainment, past occupation, equivalized household income, wealth, and subjective economic situation. These factors were separately analyzed as independent variables after regulating for covariates such as age and sex. Statistical analysis of the results was obtained by using window-based computer software devised with Statistical Packages for Social Sciences (SPSS-24).

\section{RESUlTS}

The total population of the study was 101 patients aged from 45 years to 75 years, among them $39.6 \%$ were 45 years to 59 years old, $26.73 \%$ were 60 years to 64 years old, $13.86 \%$ were 65 years to 69 years old, $16.83 \%$ were 70 years to 74 years of age, and $2.97 \%$ were $\geq 75$ years of age. Figure I demonstrated the distribution of age of the patients who were included in the study. Most of the patients $(53.46 \%)$ were female and the rest of them were male $(46.54 \%)$. Distribution of the population according to the economic status of the patients where most of the patients (59.40\%) belonged to low-income earner status, $29.70 \%$ were of lower-middle-income earners and $10.89 \%$ were among upper-middle-income earners.

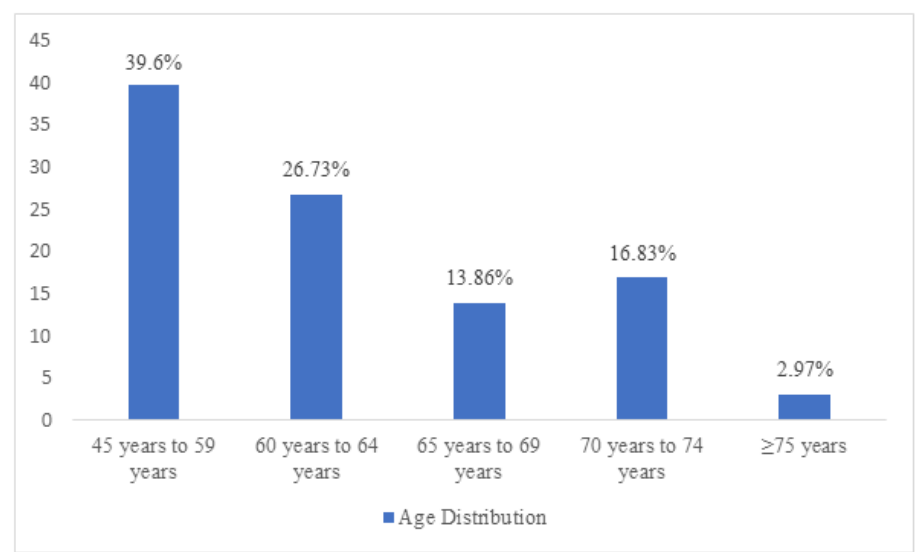

Figure I: Demonstrate and distribution of the study according to age $(n=101)$

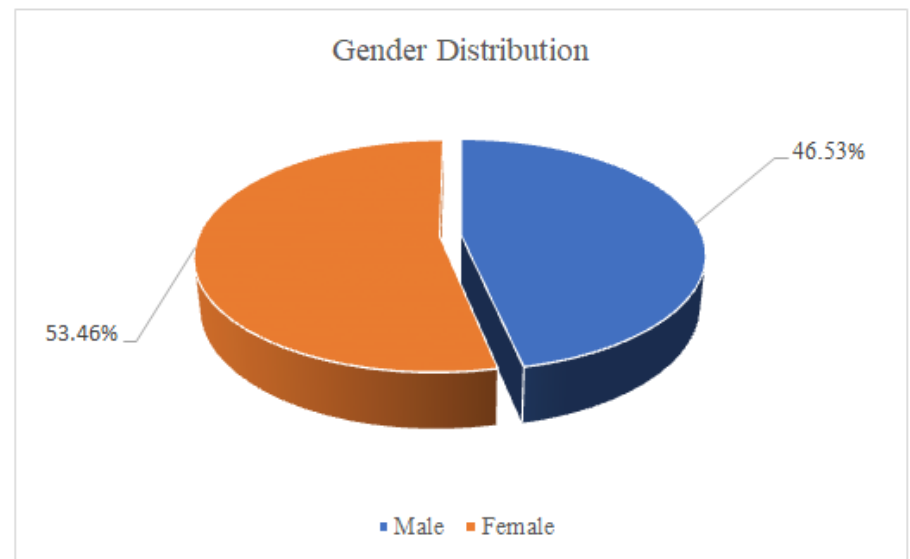

Figure II: Demonstration and distribution of the study according to $\operatorname{sex}(n=101)$

Table I: Distribution of the study according to economic status $(n=101)$

\begin{tabular}{|l|l|l|}
\hline Economic status & $\mathbf{n = 1 0 1}$ & $\mathbf{\%}$ \\
\hline Upper middle income & 46 & $45.54 \%$ \\
\hline Lower middle income & 38 & $37.62 \%$ \\
\hline Low income & 17 & $16.83 \%$ \\
\hline Total & 101 & $100 \%$ \\
\hline
\end{tabular}

\section{Discussion}

To the best of our knowledge, this study was the first to unravel the association of past and present SES with low back pain in the older class of the population. We found that participants with low SES, as measured by education, past occupation, income, subjective economic situation, and wealth, were more prone to experience low back pain compared with those 
Md Anamul Haque Milton et al; Sch J App Med Sci, Jan, 2022; 10(1): 92-96

with high SES. Moreover, these results showed that there was a socioeconomic gradient in low back pain; people with lower socioeconomic backgrounds were more likely to suffer from this issue.

Therefore, low back pain is a problem not only among deprived people but also in the whole society. Expectedly, the associations of SES with low back pain dramatically attenuated when depression was adjusted with the study. Regarding present SES, a crosssectional study from the United States found lowerincome levels to be associated with low back pain in the general population [12]. This study also indicated that associations between income and low back pain were stronger among males than females [12]. The findings of our study are also in line with those of this crosssectional study. We found that older individuals with a lower income level were more likely to suffer from low back pain in contrast to middle or upper-middle income earners. This association was strongly observed among older males. We also newly elucidated the association between other present SES, as represented by wealth or subjective economic situation, and low back pain. Accordingly, we found that participants with a lower level of both wealth and subjective economic situation were more likely to experience low back pain. The result remains the same when the fields are separately analyzed. Our further analyses which include all SES factors revealed that the impact of the more difficult subjective economic situation showed significant impact while the effects of other SES indicators were attenuated (see Table 3). Recently, the subjective economic situation has been highlighted as a new SES indicator representing the perceived relative deprivation of individuals [18, 19]. A cross-sectional study from Germany showed that subjective economic situation mediates associations between objective SES indicators (education, occupation, and income) and depressive symptoms among adults [19]. Moreover, the study reported that the association of subjective economic situation with relatively poor mental health was stronger than that of other socioeconomic status indicators [19]. Our findings have the same context with these results showing that the subjective economic situation had the highest level of impact on the general population. Furthermore, we revealed that present SES was found to be associated with low back pain among participants aged between less than 75 years to 75 years. This indicates that present SES-related inequalities persist throughout the lifespan. According to our findings, this study is among the first to reveal the associations of past SES, as measured by educational attainment and past occupation, with low back pain among older individuals. We found that participants with the lowest educational level and bluecollar workers were more likely to suffer from low back pain. Furthermore, the association between education, occupation, and low back pain was stronger among males than that of females. For educational attainment, in contrast to our study, a cross-sectional study from
France that interviewed people engaged in physical labor reported that the association of educational attainment with low back pain was no longer statistically significant when adjusting for several lifestyle indicators, including BMI and smoking [20]. The difference in educational inequalities between studies can be explained as follows: educational inequalities affect physical condition via health literacy [21], and health literacy is significantly higher in working-class people compared with that in older generations [22, 23]. Therefore, such differences between studies emerged due to demographic differences. No previous study has investigated the association of occupational inequalities with low back pain among older populations. However, numerous previous studies have indicated that heavy labor-a common issue faced by many blue-collared workers-is a risk factor of low back pain [24-27]. Our study is per the results of these prior studies. Similar to present SES, associations of past SES attenuated when all status indicators were mutually adjusted (see Table 2, Model 4). Furthermore, the association of educational attainment with low back pain was also observed among participants aged lower than 75 years to 75 years of age, indicating that educational inequalities persist throughout the lifespan. Considering the mechanism of low back pain, the role of risk factors must be determined. Previous studies have indicated that depression [13, 14], obesity [15], smoking [16], and low-income level [12] are risk factors of low back pain, which is partially per our findings. Consistent with the results of a previous study [12], present SES as represented by income, subjective economic situation, and wealth were found to be statistically associated with low back pain among the older population. Two possible pathways exist for present SES-related inequalities in health: psychosocial stress and materialistic poverty [28]. The subjective economic situation is considered to be a result of income level and is considered to represent psychosocial stress rather than materialistic poverty [28, 29]. Moreover, individuals with lower income levels are more likely to encounter barriers in accessing medical facilities [30]. In our study, among participants with low back pain, medical access to low back pain was significantly different from SES (see Additional file 1: Table S6). This indicated that barriers in accessing medical treatment would be a proxy for materialistic poverty to account for socioeconomic inequalities in triggering low back pain. A previous study indicated a relationship of influence between depression and low back pain [14]. Additionally, a causal relationship between low SES and depression has been previously reported, which supports our idea of depression as an intermediary factor. In addition to depression, numerous earlier studies have reported obesity [15] to be a risk factor for low back pain. In our study, overweight and obesity were associated with low back pain. 
Md Anamul Haque Milton et al; Sch J App Med Sci, Jan, 2022; 10(1): 92-96

The associations of obesity somewhat attenuated when depression was additionally adjusted. Previous studies have reported that such adverse healthrelated factors were strongly related to psychosocial stress [29, 30], derived from relative deprivation. Therefore, in addition to depression, obesity might contribute to triggering low back pain through psychosocial stress which is affected by SES. Furthermore, the association of drinking habits with triggering low back pain was not statistically significant in our study. However, previous studies have indicated that alcohol abuse might be associated with low back pain $[24,25]$.

The study was conducted on a limited basis which we expect to deliver a greater result if studied in a broad population. First, we examined the association of past and present SES with low back pain. Second, we analyzed a large sample size $(n=26,037)$, which is higher than that analyzed in previous studies [12, 19]. The first limitation of our study is that we were unable to distinguish between acute and chronic pain, which leads to regression dilution bias. In contrast to chronic pain, a previous study has shown that individuals with a higher income level were more likely to experience acute low back pain [12]. Hence, we believe that our results could have given a more dependable reflection of the scenario if such biases could have been avoided. Secondly, the questionnaire we used lacked information on the degree of pain. There is a possibility that low back pain might differ in the degree of pain. In fact, in our sensitivity analysis, the associations were emphasized for all models when performing the same regression analysis among participants who experienced low back pain with limitations in daily life (see Additional file 1: Table S5). Future studies should include a question about the degree of pain. Thirdly, we could not clarify the causal pathway since this is a cross-sectional study. Thus, the probable mediation by depressive conditions was not always consistent. However, we revealed that past SES and present SES were associated with low back pain. Longitudinal or cohort studies are necessary for future studies. Fourthly, our study participants were not disabled and were not eligible for the Japanese long-term care insurance system. Future study is expected to investigate the association between SES and low back pain among the population who are physically disabled. Fifthly, the generalizability of the present results to the entire Japanese population remains unclear. This is because the 30 municipalities investigated in this study were not randomly selected, and the sampling method for residents differed per the population of the municipality. It was difficult to compare our study population with the entire elderly people due to the lack of demographic characteristics in a national survey.

\section{Limitation of the study}

This was an observational study with a smallsized sample. So, the findings of this study may not reflect the exact scenario of the whole country.

\section{CONCLUSION}

We analyzed data from a cross-sectional study, unrevealing that socioeconomic inequalities were significantly associated with low back pain among the Bangladeshi population. Policymakers and clinicians must understand the nature of these inequalities.

\section{RECOMMENDATION}

This study can serve as a pilot to much larger research involving multiple centers that can provide a nationwide picture, validate regression models proposed in this study for future use and emphasize points to ensure better management and adherence.

Funding: No funding sources

Conflicts of Interest: The authors state that the publishing of this paper does not include any conflicts of interest.

Ethical approval: The study was approved by the informed consent of the participant patients.

\section{REFERENCES}

1. Kröger, H., Fritzell, J., \& Hoffmann, R. (2016). The association of levels of and decline in grip strength in old age with trajectories of life course occupational position. PLoS One, 11(5), e0155954.

2. Kondo, N., Sembajwe, G., Kawachi, I., Van Dam, R. M., Subramanian, S. V., \& Yamagata, Z. (2009). Income inequality, mortality, and self rated health: meta-analysis of multilevel studies. Bmj, 339, 1178 1181.

3. Sommer, I., Griebler, U., Mahlknecht, P., Thaler, K., Bouskill, K., Gartlehner, G., \& Mendis, S. (2015). Socioeconomic inequalities in non-communicable diseases and their risk factors: an overview of systematic reviews. BMC public health, 15(1), 1-12.

4. Etman, A., Burdorf, A., Van der Cammen, T. J., Mackenbach, J. P., \& Van Lenthe, F. J. (2012). Sociodemographic determinants of worsening in frailty among community-dwelling older people in 11 European countries. $J$ epidemiol community health, 66(12), 1116-1121.

5. Soler-Vila, H., García-Esquinas, E., León-Muñoz, L. M., López-García, E., Banegas, J. R., \& RodríguezArtalejo, F. (2016). Contribution of health behaviours and clinical factors to socioeconomic differences in frailty among older adults. J Epidemiol Community Health, 70(4), 354-360.

6. Riskowski, J. L. (2014). Associations of socioeconomic position and pain prevalence in the United States: Findings from the National Health and Nutrition Examination Survey. Pain Medicine, 15(9), 1508-1521. 
Md Anamul Haque Milton et al; Sch J App Med Sci, Jan, 2022; 10(1): 92-96

7. Gerrits, M. M., van Oppen, P., van Marwijk, H. W., Penninx, B. W., \& van der Horst, H. E. (2014). Pain and the onset of depressive and anxiety disorders. PAIN®, 155(1), 53-59.

8. Kaiho, Y., Sugawara, Y., Sugiyama, K., Tomata, Y., Endo, Y., Toyama, H., ... \& Tsuji, I. (2017). Impact of pain on incident risk of disability in elderly Japanese: cause-specific analysis. Anesthesiology, 126(4), 688696.

9. Stubbs, B., Binnekade, T., Eggermont, L., Sepehry, A. A., Patchay, S., \& Schofield, P. (2014). Pain and the risk for falls in community-dwelling older adults: systematic review and meta-analysis. Archives of physical medicine and rehabilitation, 95(1), 175-187.

10. Hoy, D., Bain, C., Williams, G., March, L., Brooks, P., Blyth, F., ... \& Buchbinder, R. (2012). A systematic review of the global prevalence of low back pain. Arthritis \& Rheumatism, 64(6), 2028-2037.

11. Currie, S. R., \& Wang, J. (2005). More data on major depression as an antecedent risk factor for first onset of chronic back pain. Psychological medicine, 35(9), 1275-1282.

12. Meyer, T., Cooper, J., \& Raspe, H. (2007). Disabling low back pain and depressive symptoms in the community-dwelling elderly: a prospective study. Spine, 32(21), 2380-2386.

13. Zhang, T. T., Liu, Z., Liu, Y. L., Zhao, J. J., Liu, D. W., \& Tian, Q. B. (2018). Obesity as a risk factor for low Back pain. Clinical spine surgery, 31(1), 22-27.

14. Shiri, R., Karppinen, J., Leino-Arjas, P., Solovieva, S., \& Viikari-Juntura, E. (2010). The association between smoking and low back pain: a metaanalysis. The American journal of medicine, 123(1), 87-e7.

15. Muntaner, C., Eaton, W. W., Miech, R., \& O'campo, P. (2004). Socioeconomic position and major mental disorders. Epidemiologic reviews, 26(1), 53-62.

16. Shaw, B. A., McGeever, K., Vasquez, E., Agahi, N., \& Fors, S. (2014). Socioeconomic inequalities in health after age 50: are health risk behaviors to blame?. Social science \& medicine, 101, 52-60.

17. Leclerc, A., Gourmelen, J., Chastang, J. F., Plouvier, S., Niedhammer, I., \& Lanoë, J. L. (2009). Level of education and back pain in France: the role of demographic, lifestyle and physical work factors. International archives of occupational and environmental health, 82(5), 643-652.

18. Goodman, E., Adler, N. E., Daniels, S. R., Morrison, J. A., Slap, G. B., \& Dolan, L. M. (2003). Impact of objective and subjective social status on obesity in a biracial cohort of adolescents. Obesity research, 11(8), 1018-1026.

19. Hoebel, J., Maske, U. E., Zeeb, H., \& Lampert, T. (2017). Social inequalities and depressive symptoms in adults: the role of objective and subjective socioeconomic status. PloS one, 12(1), e0169764.

20. Leclerc, A., Gourmelen, J., Chastang, J. F., Plouvier, S., Niedhammer, I., \& Lanoë, J. L. (2009). Level of education and back pain in France: the role of demographic, lifestyle and physical work factors. International archives of occupational and environmental health, 82(5), 643-652.

21. Van Der Heide, I., Wang, J., Droomers, M., Spreeuwenberg, P., Rademakers, J., \& Uiters, E. (2013). The relationship between health, education, and health literacy: results from the Dutch Adult Literacy and Life Skills Survey. Journal of health communication, 18(sup1), 172-184.

22. Ashida, S., Goodman, M., Pandya, C., Koehly, L. M., Lachance, C., Stafford, J., \& Kaphingst, K. A. (2011). Age differences in genetic knowledge, health literacy and causal beliefs for health conditions. Public health genomics, 14(4-5), 307-316.

23. Beauchamp, A., Buchbinder, R., Dodson, S., Batterham, R. W., Elsworth, G. R., McPhee, C., ... \& Osborne, R. H. (2015). Distribution of health literacy strengths and weaknesses across socio-demographic groups: a cross-sectional survey using the Health Literacy Questionnaire (HLQ). BMC public health, 15(1), 1-13.

24. Hestbaek, L., Leboeuf-Yde, C., \& Kyvik, K. O. (2006). Are lifestyle-factors in adolescence predictors for adult low back pain? A cross-sectional and prospective study of young twins. BMC musculoskeletal disorders, 7(1), 1-8.

25. Feldman, D. E., Shrier, I., Rossignol, M., \& Abenhaim, L. (2001). Risk factors for the development of low back pain in adolescence. American journal of epidemiology, 154(1), 30-36.

26. Mustard, C. A., Kalcevich, C., Frank, J. W., \& Boyle, M. (2005). Childhood and early adult predictors of risk of incident back pain: Ontario Child Health Study 2001 follow-up. American journal of epidemiology, 162(8), 779-786.

27. Mattila, V. M., Saarni, L., Parkkari, J., Koivusilta, L., \& Rimpelä, A. (2008). Predictors of low back pain hospitalization-a prospective follow-up of 57,408 adolescents. Pain, 139(1), 209-217.

28. Kondo, N. (2012). Socioeconomic disparities and health: impacts and pathways. Journal of epidemiology, 22(1), 2-6.

29. Schulz, A. J., Israel, B. A., Zenk, S. N., Parker, E. A., Lichtenstein, R., Shellman-Weir, S., \& AB, L. K. (2006). Psychosocial stress and social support as mediators of relationships between income, length of residence and depressive symptoms among African American women on Detroit's eastside. Social science \& medicine, 62(2), 510-522.

30. Elstad, J. I. (2016). Income inequality and foregone medical care in Europe during the great recession: multilevel analyses of EU-SILC surveys 20082013. International journal for equity in health, 15(1), 1-11. 